\title{
AC 2010-1193: A REPEATED EXPOSURE EXPERIMENT TO IMPROVE KNOWLEDGE RETENTION
}

\section{Deborah McAvoy, Ohio University}

Deborah McAvoy is an Assistant Professor in the Civil Engineering Department within the Russ College of Engineering and Technology at Ohio University. Her research interests are in the field of traffic engineering, specifically driver behaviors, human factors, highway safety and traffic operations. 


\section{A Repeated Exposure Experiment to Improve Knowledge Retention}

\section{Introduction and Background}

Improving knowledge retention of engineering students as they advance through their academic careers can enhance their quality of education and career success. However, engineering professors constantly battle the quality of student knowledge retention from course to course. Knowledge retention has been a consistent problem for students regardless of the length of break between courses, such as a one-week break or a three-month summer break. This is evidenced in a study conducted by the United States Military Academy at West Point (1). Student knowledge of Statics and Strength of Materials were examined after a three-month summer break in the Mechanics course. Faculty found that knowledge retention of the Statics and Strength of Materials topics was poor. They introduced video instruction in the Statics and Strengths course to assess the videos impact on knowledge retention. Unfortunately, the students performed 31.5 percent worse in a quiz in the Mechanics course than their final grade in the previous Statics and Strengths course. However, those students that did not watch the videos performed 44.3 percent worse, a much lower performance than those watching the videos. While the use of video instruction provides improvement in knowledge retention, additional measures may be necessary to further limit the loss of valuable knowledge between successive courses.

Another study conducted at Boise State evaluated knowledge retention through the use of repeated questions (2). Quiz questions utilized throughout a course were replicated on examinations. Students did not have access to the quiz questions after the quiz or prior to the examination. The researcher found that 70 percent of the students improved their scores on the quiz questioned replicated on the examination as compared to new questions. However, it was also found that the most recent material covered in the course received lower scores than the previous material.

A more extensive study was conducted at Western New England College to assess improvement of knowledge retention between sophomore electrical engineering students and junior electrical engineering students (3). Several modifications were made in sequential years to the electrical engineering course curriculum such as requiring summer homework, emphasizing symbolic problem solving and material repetition. Quizzes and examinations were utilized as performance measures. In each circumstance, the student performance improved indicated the positive impacts of the curriculum modifications. While the improvement on the quizzes ranged from three percent to nearly 13 percent, the improvement on the examination ranged from four percent to 20 percent.

The objective of this research study was to examine civil engineering student knowledge retention of engineering economics topics. Several modifications have been made in the past to 
the civil engineering curriculum to improve student performance in engineering economics. Prior to graduation, students are required to take the Fundamentals of Engineering examination during the October or April examination session. Engineering economics topics were previously included within another required civil engineering course resulting in Fundamentals of Engineering examination scores averaging 70.7 percent as compared to the national average of 63.1 percent. Even though student performance exceeded the national average, modifications to the curriculum which included developing a new course for engineering economics were intended to improve the student scores. Unfortunately, the scores decreased and were approximately equal to the national average. However, the engineering economics course was taken during the Spring Quarter or between March and June while the majority of the students took the Fundamental of Engineering Economics examination during the last week in April. During the last few years, the engineering economics topics included on the Fundamentals of Engineering Economics examination have been covered in the course prior to the actual date of the exam, which improved scores on the examination. However, the changes to the curriculum have not substantially improved the scores above the original average of 70 percent previously obtained. Therefore, a study was conducted throughout one academic year, including a cycle of the Fundamental of Engineering examination, to assess civil engineering student knowledge retention of engineering economics topics using a repeated-measures experiment.

\section{Description of the Study}

To assess the impact on student performance through knowledge retention, a study was conducted over the course of one academic year which consisted of three academic quarters. The analysis group included those students who enrolled in a required construction management course during their junior Fall Quarter, an elective construction management course during their junior Winter Quarter and the required engineering economics course during their Junior Spring Quarter. The construction management courses were taught by one instructor and the engineering economics course was taught by a different instructor. The student sample size included nine students that enrolled in all three courses, 32 students that enrolled in both required courses and 12 students that enrolled in the elective construction management course and the required engineering economics course. The required construction management course examined student performance in engineering economics through a quiz, an assignment and midterm examination. The quiz covered cash flow diagrams, determination of present worth, and assessing the feasibility of two projects using net present values and benefit-cost ratios. The assignment covered the comparison of two projects using net present values and benefit-cost ratios as well as the determination of present, future and annual worth. The engineering economics portion of the midterm exam covered the topics of the time value of money, compounding factors, the benefit-cost ratio, net present value, the minimum attractive rate of return and the determination of present, annual and future worth. The elective construction management course evaluated engineering economics through two quizzes and a midterm examination. Both quizzes covered the determination of present, annual and future worth as well as depreciation. The engineering economics portion of the midterm examination covered the 
time value of money, inflation, equivalent uniform annual cost and depreciation. In the required engineering economics course, student performance was measured through five quizzes, a midterm and a life-cycle cost analysis project. The engineering economics course covered introductory engineering economics topics include time value of money, cash flow diagrams, the determination of present, future, annual worth, the minimum attractive rate of return, benefit-cost analyses, and depreciation. As described above, each class covered similar engineering economics topics ranging from the time value of money to depreciation. The mean, maximum, minimum, and standard deviation for all students in each class by measurement tool are shown in Table 1.

Table 1. Student Performance in Engineering Economics Topics By Course

\begin{tabular}{|c|c|c|c|c|}
\hline \multirow{2}{*}{$\begin{array}{l}\text { Class, Measurement Tool (Total Points) } \\
\text { [Topics Covered] }^{1}\end{array}$} & \multicolumn{4}{|c|}{ Statistic } \\
\hline & Mean & Maximum & Minimum & $\begin{array}{l}\text { Standard } \\
\text { Deviation }\end{array}$ \\
\hline \multicolumn{5}{|l|}{ Required Construction Management Course } \\
\hline $\begin{array}{l}\text { Quiz (10) } \\
{[C F D, P W, A W, F W, N P V, B / C]}\end{array}$ & 6.15 & 10 & 0 & 2.181 \\
\hline $\begin{array}{l}\text { Assignment (20) } \\
{[P W, A W, F W, N P V, B / C]}\end{array}$ & 14.00 & 20 & 0 & 6.801 \\
\hline $\begin{array}{l}\text { Midterm (16) } \\
{[C F D, P W, N P V, B / C, M A R R]}\end{array}$ & 11.82 & 16 & 3 & 3.459 \\
\hline \multicolumn{5}{|l|}{ Elective Construction Management Course } \\
\hline $\begin{array}{l}\text { Quiz } 1(10) \\
{[P W, A W, F W]}\end{array}$ & 8.00 & 10 & 5 & 1.354 \\
\hline $\begin{array}{l}\text { Quiz } 2(10) \\
{[T X, D E P]}\end{array}$ & 9.23 & 10 & 7 & 1.166 \\
\hline $\begin{array}{l}\text { Midterm (35) } \\
{[I N, D E P, T X, A W, N P V]}\end{array}$ & 28.62 & 35 & 21 & 3.906 \\
\hline \multicolumn{5}{|l|}{ Required Engineering Economics Course } \\
\hline $\begin{array}{l}\text { Quiz } 1(10) \\
{[C F D]}\end{array}$ & 9.51 & 10 & 0 & 1.528 \\
\hline $\begin{array}{l}\text { Quiz } 2(20) \\
{[P W, A W, F W]}\end{array}$ & 19.33 & 20 & 11 & 1.424 \\
\hline $\begin{array}{l}\text { Quiz } 3(18) \\
{[P W, A W, F W]}\end{array}$ & 15.82 & 18 & 0 & 4.811 \\
\hline $\begin{array}{l}\text { Quiz } 4(6) \\
{[C F D, P W, A W, F W, N P V]}\end{array}$ & 4.88 & 6 & 0 & 1.505 \\
\hline $\begin{array}{l}\text { Quiz } 5(9) \\
{[B / C, M A R R, D E P]}\end{array}$ & 6.98 & 9 & 2 & 2.074 \\
\hline $\begin{array}{l}\text { Midterm }(100) \\
{[C F D, P W, A W, F W, N P V, B / C, M A R R, D E P]}\end{array}$ & 72.25 & 100 & 45 & 12.013 \\
\hline $\begin{array}{l}\text { Project }(85) \\
{[L C C]}\end{array}$ & 76.167 & 85 & 55 & 8.1484 \\
\hline
\end{tabular}

1: CFD: Cash Flow Diagrams, PW: Present Worth, AW: Annual Worth, FW: Future Worth, NPV: Net Present Value, B/C: Benefit-to-Cost Ratio, MARR: Minimum Attractive Rate of Return, TX: Tax Rates and Tax Savings, DEP: Depreciation, IN: Inflation, LCC: Life Cycle Cost Analysis 
The students were also subdivided into subgroups by number of courses enrolled; all three courses, the required courses (construction management and engineering economics) and only the engineering economics course. Due to potential bias related to the different instructors between the construction management courses and the engineering economics courses, an evaluation was conducted using only the performance measures in the engineering economics course. The mean and standard deviation for each measurement tool for the three groups as assessed in the engineering economics course are shown in Table 2.

Table 2. Student Performance by Number of Courses Enrolled

\begin{tabular}{|c|c|c|c|c|c|c|}
\hline \multirow{2}{*}{$\begin{array}{c}\text { Subgroup } \\
\text { and } \\
\text { Measurement } \\
\text { Tool (Total } \\
\text { Points) }\end{array}$} & \multicolumn{2}{|c|}{$\begin{array}{c}\text { Enrolled in Three } \\
\text { Courses }\end{array}$} & \multicolumn{2}{|c|}{$\begin{array}{c}\text { Enrolled in Two } \\
\text { Courses }\end{array}$} & \multicolumn{2}{|c|}{$\begin{array}{c}\text { Enrolled in One } \\
\text { Course }\end{array}$} \\
\hline & Mean & $\begin{array}{l}\text { Standard } \\
\text { Deviation }\end{array}$ & Mean & $\begin{array}{l}\text { Standard } \\
\text { Deviation }\end{array}$ & Mean & $\begin{array}{l}\text { Standard } \\
\text { Deviation }\end{array}$ \\
\hline Quiz 1 (10) & 9.44 & 1.130 & 9.81 & 0.634 & 9.00 & 2.535 \\
\hline Quiz 2 (20) & 19.67 & 0.500 & 19.62 & 0.637 & 18.60 & 2.354 \\
\hline Quiz 3 (18) & 15.33 & 5.809 & 16.15 & 4.855 & 15.40 & 4.517 \\
\hline Quiz 4 (6) & 4.89 & 1.965 & 4.85 & 1.488 & 4.87 & 1.356 \\
\hline Quiz 5 (9) & 6.78 & 1.856 & 6.85 & 2.292 & 7.20 & 1.897 \\
\hline $\begin{array}{r}\text { Midterm } \\
(100)\end{array}$ & 74.44 & 11.844 & 70.58 & 10.23 & 72 & 13.601 \\
\hline Project $(85)$ & 78.56 & 10.026 & 74.25 & 8.51 & 77.47 & 5.69 \\
\hline Final Grade & 0.8432 & 0.072 & 0.8065 & 0.069 & 0.8338 & 0.071 \\
\hline
\end{tabular}

\section{Statistical Analysis Methodology}

Utilizing quiz scores, examinations and project grades that covered similar materials in each of the three courses, a repeated-measures analysis of variance was conducted to assess knowledge retention to determine if the differences in the student scores were significant based exposure to the topic. The repeated-measures analysis of variance was used to compare the mean of the dependant variables after multiple exposures to the same topic; engineering economics. The dependant variables were student scores which were considered continuous data or data assuming a range of numerical variables. The independent variable was considered discrete and categorical data where the data belonged to only one group; enrolled in one course, enrolled in two courses or enrolled in three courses. The repeated-measures analysis of variance has several underlying assumptions (4). The sample must be randomly selected from the population. It was assumed for this analysis that the population was Civil Engineering students and the sample of students taking the three courses was random. The dependant variables must exhibit a distribution that is approximately normal while the variance for the dependant variables and the correlation coefficients between the pair must also be similar. The effect degrees of freedom were equal to $\mathrm{k}-1$, where $\mathrm{k}$ is the number of levels. The error degrees of freedom were calculated by $(n-1)(k-1)$, where $n$ was the number of participants. When variables are dependant, the total 
sum of squares $\left(\mathrm{SS}_{\mathrm{T}}\right)$ used in the analysis of variance is partitioned into the variation among individuals $\left(\mathrm{SS}_{\mathrm{I}}\right)$, the variation among test occasions $\left(\mathrm{SS}_{\mathrm{o}}\right)$ and the residual variation $\left(\mathrm{SS}_{\mathrm{Res}}\right)$. If the calculated F-ratio is greater than F-critical obtained in available statistical tables, the null hypothesis is rejected indicating that the means are not equal.

In order to determine the number of students required to assure a statistically valid representative sample while protecting for both Type I and Type II errors, the following equation was utilized (4):

$$
\mathrm{n}=\frac{\left(\mathrm{Z}_{\beta}-\mathrm{Z}_{\alpha / 2}\right)^{2} \times \sigma^{2}}{\varepsilon^{2}}
$$

Where:

$$
\begin{aligned}
& \mathrm{Z}_{\beta}=\begin{array}{c}
\text { critical value corresponding to a given value of } \beta \text { in the upper tail of the standard } \\
\text { normal distribution }
\end{array} \\
& \mathrm{Z}_{\alpha}=\text { critical value corresponding to a given value of } \alpha / 2 \text { in the lower and upper tail of the } \\
& \text { standard normal distribution } \\
& \sigma=\text { standard deviation of the difference } \\
& \varepsilon=\text { detectable difference in the means }
\end{aligned}
$$

Various sample size requirements were calculated using a level of confidence of 95 percent or alpha equal to 0.05 and a power of 80 percent or beta equal to 0.20 . Based upon a standard deviation of 0.07 , the number of students required to determine a difference in grade is shown in Table 3.

Table 3. Sample Size Requirements for Statistical Significance

\begin{tabular}{|c|c|}
\hline $\begin{array}{c}\text { Percent Difference } \\
\text { in Grade }\end{array}$ & $\begin{array}{c}\text { Number of } \\
\text { Students Required }\end{array}$ \\
\hline $1 \%$ & 385 \\
\hline $2.5 \%$ & 62 \\
\hline $5 \%$ & 16 \\
\hline $7.5 \%$ & 7 \\
\hline $10 \%$ & 4 \\
\hline
\end{tabular}

Using the sample size of nine students that enrolled in all three courses, a grade difference of 6.5 percent would be detectable whereas a difference of 3.5 percent can be detected among the 32 students taking both of the required courses.

\section{Data Analysis and Results}

The null hypothesis stated that there were no differences in student scores regardless of the exposure to engineering economics, in other words whether they were exposed to economics in one, two or three courses. For this analysis, the grades received in the required engineering 
economics course were utilized to limit the bias associated with different instructors. Based upon the scores obtained in the required engineering economics course, the students taking only one course had an average grade of 83.38 percent and expectedly the students taking all three courses had an average grade of 84.32 percent. However, the students enrolled in two courses received an average grade of 80.65 percent, lower than students taking one class and those taking three classes. Prior to conducting the statistical analysis, the student scores were examined for normality through examination of probability plots, skewness and kurtosis. The examination found slight deviations from normality, but not significant enough to impact or bias the results of the analysis of variance. For the repeated-measures analysis of variance, the assumption of sphericity was analyzed to determine if the variances of the differences between the various student groups were similar. The Mauchly's test found that the variance of the differences was similar therefore the assumption of sphericity was validated. The analysis did not find statistically significant differences in student performance regardless of how many courses were taken that exposed students to similar engineering economics topics. The Pearson's effect size was calculated as 0.27 and 0.35 for the comparisons which indicate the repeated exposure of engineering economics on knowledge retention is a medium effect.

Due to the extremely limited sample size in regards to the number of students that enrolled in all three courses, a secondary repeated-measures analysis of variance was conducted to examine differences in knowledge retention between the two required courses in which 32 students had enrolled. The data utilized for this analysis included the average student score for each measurement tool in each course. The mean score for the required construction management course was 68.55 percent while the mean score for the required engineering economics course was 83.05 percent. The data was examined for violations of the assumptions of the repeatedmeasures analysis of variance test. It was determined the slight deviations from normality were not significant enough to impact or bias the results. The analysis found a significant difference in performance between the two courses with an F-calculated of 28.90. The analysis also found that 33.6 percent of the variability of the student scores could be explained by the repeated exposure to engineering economics. A correlation analysis finds that performance in the first required course is positively related to performance in the second required course based upon a Pearson's correlation coefficient of 0.502 .

\section{Discussion of the Results}

While the intention of this study was to shed light on the positive impact of repeated exposure of engineering economics on knowledge retention, the results from the repeated-measures analysis of variance indicates exposure throughout an academic year does not necessarily improve student performance. However, the average grade for the senior students taking the engineering economics course was an 81.5 percent and the score on the Fundamentals of Engineering examination for the engineering economics section was 86 percent, ten percent above the national average. It is important to note the juniors in the engineering economics course, whom 
accounted for 58 percent of the students, had not taken the Fundamentals of Engineering examination at the time of this study. Additional analyses will be required to assess the ultimate impact of repeated exposure upon the results of the Fundamentals of Engineering examination. Unfortunately, a full calendar year will have passed between the completion of the engineering economics course and the Fundamentals of Engineering examination for the junior-level students.

\section{Bibliography}

1. Klosky, James and Elizabeth Bristow, The Effect of On-Demand Instructional Videos on Medium-Term Retention of Mechanics Skills, Compendium of Technical Papers of the 2008 Annual Conference and Exposition, American Society for Engineering Education, Pittsburgh, June 22-25, 2008.

2. Davis, Kirsten, Improving Motivation and Knowledge Retention with Repeatable LowStakes Quizzing, Compendium of Technical Papers of the 2009 Annual Conference and Exposition, American Society for Engineering Education, Austin, Texas, June 14-17, 2009.

3. Northrup, Steven and John Burke, Continuous Improvement in Electrical Engineering Student Outcomes, Compendium of Technical Papers of the 2008 Annual Conference and Exposition, American Society for Engineering Education, Pittsburgh, June 22-25, 2008.

4. Hinkle, Dennis, William Wiersma, and Stephen Jurs. Applied Statistics for the Behavioral Sciences, Fifth Edition. New York, Houghton Mifflin Company, 2003. 